\title{
Identifying asymptomatic Leishmania infections in non-endemic villages in Gedaref state, Sudan
}

\author{
Nouh Saad Mohamed ${ }^{1,2,3^{*}} \mathbb{0}$, Hussam A. Osman4, Mohamed S. Muneer ${ }^{5,6,7}$, Abdallah M. Samy ${ }^{8}$, \\ Ayman Ahmed ${ }^{9}$, Anwar O. Mohammed ${ }^{10}$, Emmanuel Edwar Siddig 11,12,13, Muzamil M. Abdel Hamid ${ }^{9}$, \\ Mohamed Siralkhatim Ali ${ }^{14,15}$, Rihab A. Omer ${ }^{3,16}$ and Arwa H. Elaagip ${ }^{9,17}$
}

\begin{abstract}
Objectives: Infection with the causative agent of visceral leishmaniasis (VL) may be either symptomatic or asymptomatic. In this study we aimed at investigating the prevalence of asymptomatic infections of leishmania in nonendemic villages in Gedaref state, Sudan. A descriptive cross-sectional study conducted during September and October 2014. Blood samples were collected for serological and molecular analysis. Sticky-traps, knockdown spray and CDC-miniature light traps were used for the collection of sandflies.

Results: Ninety-Five participants were included; 52 from Abukishma, 15 Algadamblia Tirfa, 25 Abualnaja and 3 were from Algadamblia Aljabal. Females constituted 56 (58.9\%) of the study participants while males were 39 (41.1\%). The most frequent age group was $>40$-years (54.7\%). Balanites/Acacia trees were the most planted tree inside the houses; 78 (82.1\%). Also, 85 (89.5\%) of the participants breed animals inside the house. DAT test revealed 5 positive participants (5.2\%). 4/5 DAT positive were past VL infection. PCR detected 35 (36.8\%) positive participants. A total of 31/35 was considered asymptomatic infections based on PCR. Households planted Balanites/Acacia trees or breed domestic animals were found in high percentages with L. donovani PCR positive participants (60.1\%, 91.4\%). No statistically significant was found for VL associated risk factors and VL asymptomatic participants.
\end{abstract}

Keywords: Visceral leishmaniasis, Asymptomatic infection, Non-endemic villages, Gedaref state, Sudan

\section{Introduction}

Visceral leishmaniasis (VL), also known as new world leishmaniasis or Kala-azar, is a neglected tropical disease caused by protozoan parasites of the Leishmania donovani complex. The parasites are transmitted through bites of infected phlebotomine sandfly vectors [1]. The disease is endemic in southern Europe, Latin America, Asia, and Africa with an estimated burden of $875 ; 3668 ; 45,119$; and 8569 cases per annum, respectively [1]. Individuals with $\mathrm{VL}$ are clinically defined as symptomatic when there is a prolonged, persistent fever (i.e., longer than 2 weeks) and wasting with progressive spleen enlargement $[2,3]$.

\footnotetext{
*Correspondence: nouh.s.mohamed@nuri.nu.edu.sd

1 Department of Parasitology and Medical Entomology, Faculty of Medical Laboratory Sciences, University of Sinner, 11111 Khartoum, Sudan

Full list of author information is available at the end of the article
}

However, subclinical infections can as well advance to apparent illness [4]. VL has long been endemic in Sudan, and it remains a significant public health problem most notably in areas around Sudan-Ethiopia borders and White Nile State in central-eastern and western Sudan. [5-7]. These areas are characterized by high incidence, morbidity, and mortality [8]. In Sudan, only Phlebotomus orientalis has been implicated as vector to transmit VL despite the presence of other circulating sandfly species; P. papatasi, P. saevus, P. rodhaini, Sergentomyia clydei, S. antennata, S. sckwetzi, S. Africana, and S. squamipleuris [9]. In eastern Sudan, there are consistently high rates of infection, with about $16 \%$ death rate attributed to VL [5]. However, in most endemic regions, the classical form of the disease is only manifested in about $20 \%$ of the infected population, while the majority remain asymptomatic and 
may progress to symptomatic state or resolve the infection $[10,11]$. These asymptomatic populations remain a potential reservoir for maintaining transmission cycles in endemic areas, and as well as re-introducing infections in non-endemic regions [12]. Although, investigation and analysis of VL risk factors have been conducted in various VL foci $[10,12-16]$. This study, therefore aimed at investigating the prevalence of asymptomatic infections in non-endemic villages in Gedaref state, Sudan.

\section{Main text}

\section{Materials and methods}

\section{Study design and study area characteristics}

A descriptive cross-sectional hospital-based study was conducted in Gedaref State, eastern Sudan between September and October 2014. Four villages were selected based on the reports of the presence of 4 new VL cases from the Leishmaniasis Control Program, Ministry of Health, Gedaref State, Sudan (Unpublished data). The four villages were Abukishma $\left(14.05328^{\circ} \mathrm{N}, 035.12329^{\circ} \mathrm{E}\right)$, Algadamblia Tirfa $\left(14.01715^{\circ} \mathrm{N}, 035.00059^{\circ} \mathrm{E}\right)$ Algadamblia Aljabal $\left(14.02141^{\circ} \mathrm{N}, 035.00466^{\circ} \mathrm{E}\right)$ and Abualnaja $\left(13.97850^{\circ} \mathrm{N}, 035.30479^{\circ} \mathrm{E}\right)$ (Fig. 1).

\section{Data collection tools and procedures}

Participants with chronic diseases such as Tuberculosis and HIV, and those refused to provide informed consent were excluded from the study. A total of 95 participants were recruited using a simple random selection method; 52 from Abukishma, 15 Algadamblia Tirfa, 25 Abualnaja and 3 from Algadamblia Aljabal. All participants' demographical data including age, gender, occupation, marital status, and education, as well as household information concerning the type of the house, sleeping habitat and insect control strategies used, were collected.

\section{Collection and processing of blood samples}

Three milliliters of venous blood was collected from each participant from the antecubital vein by a phlebotomist. Blood samples were slowly poured into Potassium Ethylene diamine tetraacetic acid (K3-EDTA) containers to prevent coagulation. Each blood sample was gently and adequately mixed by inverting the container to avoid hemolysis, clotting, or platelet aggregation [17]. The samples were centrifuged at $1008 \mathrm{~g}$ for $5 \mathrm{~min}$ to separate plasma and buffy coat. Plasma and buffy coat were collected into separate tubes and stored at $-20{ }^{\circ} \mathrm{C}$ for serological and molecular analysis.

\section{Serological analysis}

The serological analysis was performed using the direct agglutination test (DAT). DAT was performed in the Biomedical Research Laboratories of Ahfad University for Women-Sudan following the protocol described by El Harith et al. [18]. The antigen was prepared from the local endemic strain (MHOM/68/1-S). In brief, plasma diluent was made up of $\mathrm{NaCl}$ and gelatin of $75 \%(\mathrm{v} / \mathrm{v})$, warmed at $60{ }^{\circ} \mathrm{C}$ for $15 \mathrm{~min} .50 \mu \mathrm{l}$ of plasma diluent was dispensed into the wells of the $\mathrm{V}$-shaped microtiter plates. $1 \mu \mathrm{l}$ of each patient plasma were added. A serial dilution was
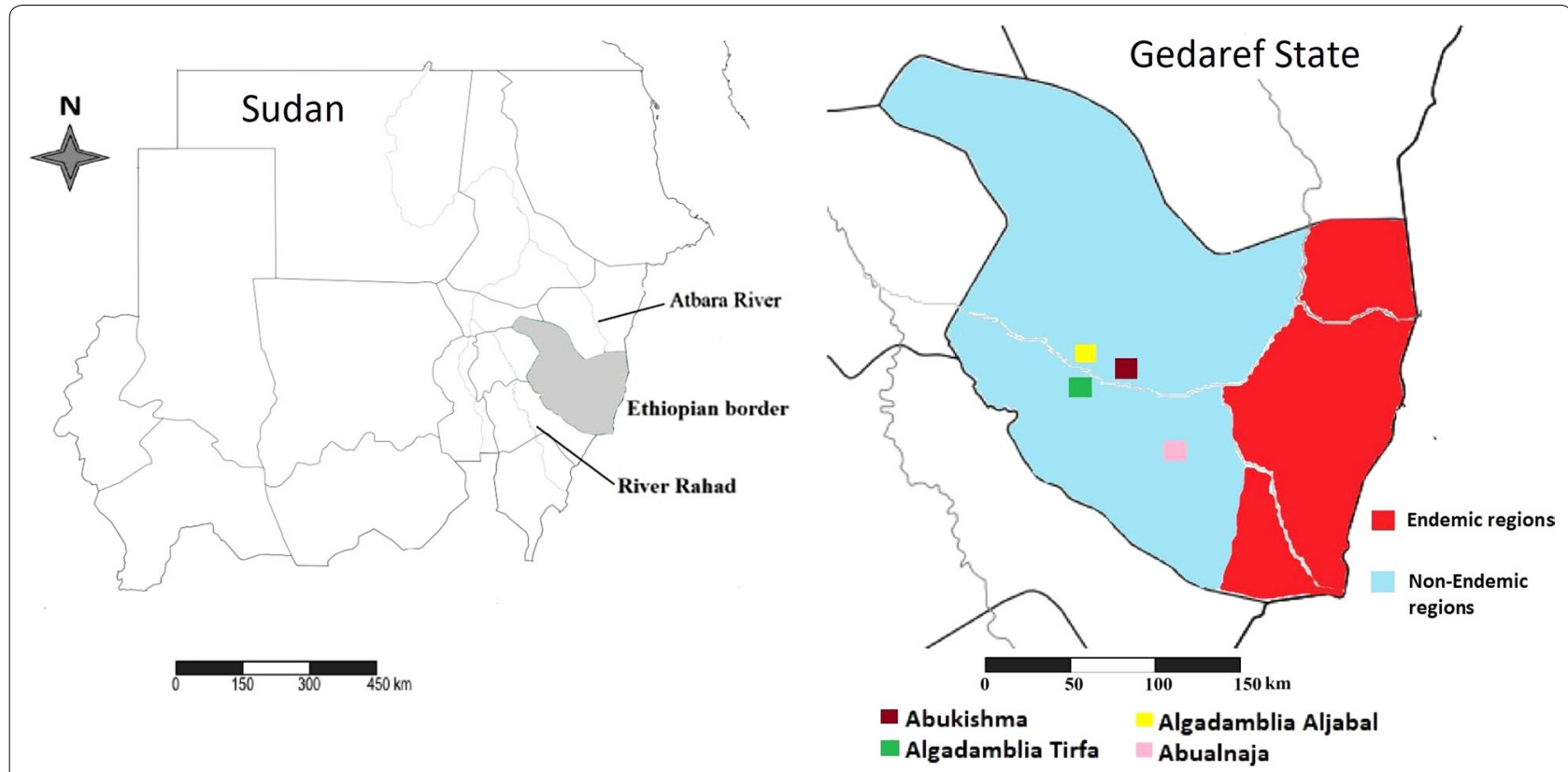

Fig. 1 Map of Gedaref State showing the study villages in Gedaref state, Sudan 
done. $50 \mu \mathrm{l}$ of the prepared antigen was added to all the wells and incubated for $18 \mathrm{~h}$ at $25^{\circ} \mathrm{C}$. Results were interpreted via visualizing agglutination. A serial of titers was recorded. A titer of $\leq 1: 800$ was considered negative, a titer of 1:1600 was considered as borderline and a titer of $\geq 1: 3200$ was considered positive for VL according to El Harith et al. [19].

\section{Molecular analysis}

DNA was extracted from the buffy coats using the guanidine hydrochloride extraction method described previously [20]. The primers 18S-LEISH forward: 5'GCTGTG CAGGTTTGTTCCTG' 3 and 18S-LEISH reverse: 5'GGA CGCACTAAACCCCTCAA'3, were used to amplify a band of 357 bp within the 18S rRNA gene of L. donovani. PCR was performed in $25 \mu \mathrm{l}$ reaction volume using i-Taq PreMix Kit (iNtRON, South Korea) according to the manufacturer's instructions. PCR was performed on a thermocycler (SensoQuest, Germany). Cycling conditions were: initial denaturation at $95{ }^{\circ} \mathrm{C}$ for $5 \mathrm{~min}, 35$ cycles of denaturation for $1 \mathrm{~min}$ at $94{ }^{\circ} \mathrm{C}$, annealing for $1 \mathrm{~min}$ at $58.4{ }^{\circ} \mathrm{C}$ and elongation for $2 \mathrm{~min}$ at $68^{\circ} \mathrm{C}$. Also, a final elongation for $15 \mathrm{~min}$ at $72{ }^{\circ} \mathrm{C}$. Distilled water was used as a negative control, and known L. donovani DNA was used as a positive control in each run. After amplification, the products were separated on a $2 \%$ agarose gel in TBE buffer and stained with $3 \mu \mathrm{l}$ ethidium bromide. $5 \mu \mathrm{l}$ of each PCR product were loaded on the gel and subjected to a current of $80 \mathrm{~V}$ for $90 \mathrm{~min}$. The PCR products were visualized using ultraviolet trans-illuminator. The molecular weights of the amplicons were estimated with a standard 100 bp DNA ladder.

\section{Collection and morphological identification of sandflies}

Based on the nocturnal periodicity of the sandflies [21], sandflies collection was carried out simultaneously inside and outside the houses of the recruited participants between 18.00 and $06.00 \mathrm{~h}$ on four subsequent nights. 25 Sticky oil traps and 15 CDC miniature light traps were situated at $30 \mathrm{~cm}$ above ground level inside and outside the houses. Besides, the pyrethroid spray catch (PSC) method using Flytex aerosol was used between 06:00 and 9:00 $\mathrm{h}$ to collect sandflies inside the rooms of the participants. Collected sandflies were preserved in RNAlater solution (iNtRON, South Korea). The identification process was done under a binocular microscope at $40 \times$ lens following the identification keys published previously $[22,23]$.

\section{Statistical analysis}

Statistical analysis was performed using the statistical package for social sciences (SPSS. Version 16). Demographical data like age, gender, as well as household information, and the use of bed nets, insect bites frequency were analyzed. Variables considered as risk factors, including vegetation in/around the house, breeding animals, insect bites, and insect control methods were analyzed using the Chi square test.

\section{Results \\ Participants' demographic data}

Majority of the study participants were females; 56 (58.9\%). Males constituted 39 (41.1\%). Frequency of participants aged $>40$ years was $54.7 \%$, and those $\leq 40$ years were $45.3 \%$. The majority of participants $51(53.7 \%)$ were farmers. Almost two-thirds of the participants have thatched houses with windows (55.8\%). Participants who do not visit any forests were $67.4 \%$. Participants who have vegetations inside the house were higher than those who have vegetations around the house; $78(82.1 \%)$ and 17 (17.9\%) respectively. Animal breeding inside the house was frequent than breeding animals outside the house; 85 (89.5\%) and 10 (10.5\%), respectively. Complaints of nocturnal and crepuscular insect bites were reported by 67 (70.5\%) participants and the most frequent insects biting control method was using bed nets 58 (61.1\%) (Table 1).

\section{Prevalence of Leishmania donovani complex antigen}

An overall prevalence of $5.2 \% \mathrm{VL}$ infections were detected among the study participants. Four participants had a titer of $>1: 6400$ and one had a titer of 1:3200. Most of the participants did not have VL infection previously (95.8\%), whereas $4 / 5$ of those with a positive DAT titer have been previously infected with VL (Table 2).

\section{PCR results}

Leishmania donovani DNA was found in 35 out of 95 samples (36.8\%). Five of the samples were found to be positive using the DAT test were also positive by PCR. The distribution of VL infected participants detected by PCR according to the location of sample collection is also illustrated in Table 2. Representative samples of PCR amplification of the 18S rRNA gene of $L$. donovani is shown in Additional file 1.

\section{Abundance and distribution of sandflies vectors}

A total of 220 sandflies were collected. All the collected sandflies were identified as $P$. papatasi, and none of the flies were identified as $P$. orientalis. Of the 220 sandflies, a total of 93 were collected using sticky oil traps, 73 collected using CDC light traps and 54 were collected by PSC method. 105 sandflies were collected from Abukishma, 58 from Abualnaja, 36 from Algadamblia Aljabal, and 21 from Algadamblia Tirfa. The difference of the sandflies abundance between the different villages had a statistical significance, $P$ value 0.006 (see also Table 2). 
Table 1 Demographic and household information of the study participants

\begin{tabular}{|c|c|c|c|c|c|c|}
\hline & \multicolumn{4}{|c|}{ Study villages } & \multirow[t]{2}{*}{ Total } & \multirow[t]{2}{*}{ P value } \\
\hline & Abukishma & Algadamblia Aljabal & Algadamblia Tirfa & Abualnaja & & \\
\hline \multicolumn{7}{|l|}{ Gender } \\
\hline Male & $18(46.2 \%)$ & $1(2.6 \%)$ & $12(30.8 \%)$ & $8(20.5 \%)$ & $39(41.1 \%)$ & 0.010 \\
\hline Female & 34 (60.7\%) & $2(3.6 \%)$ & $3(5.4 \%)$ & 17 (30.4\%) & $56(58.9 \%)$ & \\
\hline \multicolumn{7}{|l|}{ Participants age } \\
\hline$\leq 40$ years & 19 (44.2\%) & $3(7.0 \%)$ & $9(20.9 \%)$ & $12(27.9 \%)$ & $43(45.3 \%)$ & 0.318 \\
\hline$>40$ years & $33(63.5 \%)$ & $0(0.0 \%)$ & $6(11.5 \%)$ & $13(25.0 \%)$ & $52(54.7 \%)$ & \\
\hline \multicolumn{7}{|l|}{ Marital status } \\
\hline Married & $46(61.3 \%)$ & $1(1.3 \%)$ & $10(13.3 \%)$ & $18(24.1 \%)$ & 75 (78.9\%) & 0.033 \\
\hline Single & $6(30.0 \%)$ & $2(10.0 \%)$ & $5(25.0 \%)$ & 7 (35.0\%) & $20(21.1 \%)$ & \\
\hline \multicolumn{7}{|l|}{ Education status } \\
\hline Illiterate & $7(50.0 \%)$ & $0(0.0 \%)$ & $2(14.3 \%)$ & $5(35.7 \%)$ & $14(14.7 \%)$ & 0.004 \\
\hline Khalwa & 31 (79.5\%) & $1(2.6 \%)$ & $2(5.1 \%)$ & $5(12.8 \%)$ & $39(41.1 \%)$ & \\
\hline Educated & $14(50.0 \%)$ & $2(7.1 \%)$ & $11(17.9 \%)$ & 15 (25.0\%) & $42(44.2 \%)$ & \\
\hline \multicolumn{7}{|l|}{ Occupation } \\
\hline Farmer & $34(66.7 \%)$ & $1(2.0 \%)$ & $7(13.7 \%)$ & $9(17.6 \%)$ & $51(53.7 \%)$ & 0.230 \\
\hline Student & $7(41.2 \%)$ & $2(11.8 \%)$ & $4(23.5 \%)$ & $4(23.5 \%)$ & $17(17.9 \%)$ & \\
\hline Teacher & $3(42.9 \%)$ & $0(0.0 \%)$ & $2(28.6 \%)$ & $2(28.6 \%)$ & 7 (7.4\%) & \\
\hline Housewife & $5(45.5 \%)$ & $0(0.0 \%)$ & $1(9.1 \%)$ & $5(45.5 \%)$ & $11(11.6 \%)$ & \\
\hline Driver & $3(33.3 \%)$ & $0(0.0 \%)$ & $1(11.1 \%)$ & $5(55.6 \%)$ & $9(9.5 \%)$ & \\
\hline \multicolumn{7}{|l|}{ Household type } \\
\hline Thatched with windows & $21(39.6 \%)$ & $3(5.7 \%)$ & $13(24.5 \%)$ & $16(30.2 \%)$ & $53(55.8 \%)$ & 0.007 \\
\hline Thatched without windows & $31(75.6 \%)$ & $0(0.0 \%)$ & $1(2.4 \%)$ & $9(22.0 \%)$ & $41(43.2 \%)$ & \\
\hline Bricked house & $0(0.0 \%)$ & $0(0.0 \%)$ & $1(100 \%)$ & $0(0.0 \%)$ & $1(1.1 \%)$ & \\
\hline \multicolumn{7}{|l|}{ Forests visiting } \\
\hline Yes & $23(74.2 \%)$ & $0(0.0 \%)$ & $1(3.2 \%)$ & 7 (22.6\%) & $31(32.6 \%)$ & 0.045 \\
\hline No & $29(45.3 \%)$ & $3(4.7 \%)$ & $14(21.9 \%)$ & $18(28.1 \%)$ & $64(67.4 \%)$ & \\
\hline \multicolumn{7}{|l|}{ Vegetations } \\
\hline Inside the house & $41(52.6 \%)$ & $3(3.8 \%)$ & $13(16.7 \%)$ & $21(26.9 \%)$ & $78(82.1 \%)$ & 0.870 \\
\hline Around the house & $11(64.7 \%)$ & $0(0.0 \%)$ & $2(11.8 \%)$ & $4(23.5 \%)$ & $17(17.9 \%)$ & \\
\hline \multicolumn{7}{|l|}{ Animal breeding } \\
\hline Inside the house & $44(51.8 \%)$ & $3(3.5 \%)$ & $14(16.5 \%)$ & $24(28.2 \%)$ & $85(89.5 \%)$ & 0.358 \\
\hline Outside the house & $8(80.0 \%)$ & $0(0.0 \%)$ & $1(10.0 \%)$ & $1(10.0 \%)$ & $10(10.5 \%)$ & \\
\hline \multicolumn{7}{|l|}{ Insects biting } \\
\hline Crepuscular & $13(100 \%)$ & $0(0.0 \%)$ & $0(0.0 \%)$ & $0(0.0 \%)$ & $13(13.7 \%)$ & 0.001 \\
\hline Nocturnal & $5(33.3 \%)$ & $0(0.0 \%)$ & $10(66.7 \%)$ & $0(0.0 \%)$ & $15(15.8 \%)$ & \\
\hline Crepuscular and nocturnal & $34(5.7 \%)$ & $3(4.5 \%)$ & $5(7.5 \%)$ & $25(37.3 \%)$ & $67(70.5 \%)$ & \\
\hline \multicolumn{7}{|l|}{ Insects control } \\
\hline Aerosols & $0(0.0 \%)$ & $0(0.0 \%)$ & $0(0.0 \%)$ & $3(100 \%)$ & $3(3.2 \%)$ & 0.001 \\
\hline Aerosols and bed nets & $0(0.0 \%)$ & $0(0.0 \%)$ & $0(0.0 \%)$ & $3(100 \%)$ & $3(3.2 \%)$ & \\
\hline Bed nets & $35(60.3 \%)$ & $3(5.2 \%)$ & $13(22.4 \%)$ & $7(12.1 \%)$ & $58(61.1 \%)$ & \\
\hline Repellants & $0(0.0 \%)$ & $0(0.0 \%)$ & $0(0.0 \%)$ & $1(100 \%)$ & $1(1.1 \%)$ & \\
\hline Smoke & $2(16.7 \%)$ & $0(0.0 \%)$ & $1(8.3 \%)$ & $9(75.0 \%)$ & $12(12.6 \%)$ & \\
\hline Smoke and bed nets & $2(100 \%)$ & $0(0.0 \%)$ & $0(0.0 \%)$ & $0(0.0 \%)$ & $2(2.1 \%)$ & \\
\hline No control method & $13(76.5 \%)$ & $0(0.0 \%)$ & $1(5.9 \%)$ & $3(17.6 \%)$ & $17(17.9 \%)$ & \\
\hline
\end{tabular}


Table 2 the distribution of DAT and PCR tests for the detection of VL positive participants and the different methods used for the collection of sandflies in the study villages

\begin{tabular}{|c|c|c|c|c|c|c|}
\hline & \multicolumn{4}{|l|}{ Villages } & \multirow[t]{2}{*}{ Total } & \multirow[t]{2}{*}{$P$ value } \\
\hline & Abukishma & Algadamblia Aljabal & Algadamblia Tirfa & Abualnaja & & \\
\hline \multicolumn{7}{|l|}{ DAT and PCR results } \\
\hline No. positive for DATa (\%) & $2(40.0 \%)$ & $1(20.0 \%)$ & $2(40.0 \%)$ & $0(0.0 \%)$ & $5(5.3 \%)$ & 0.714 \\
\hline No. positive for PCR (\%) & $19(54.3 \%)$ & $2(5.7 \%)$ & $7(20.0 \%)$ & $7(20.0 \%)$ & $35(36.8 \%)$ & \\
\hline No. examined (\%) & $52(54.7 \%)$ & $3(3.2 \%)$ & $15(15.8 \%)$ & $25(26.3 \%)$ & $95(100 \%)$ & \\
\hline \multicolumn{7}{|l|}{ Distribution of sandflies } \\
\hline No. (\%) caught using PSC & $23(42.6 \%)$ & $14(25.9 \%)$ & $7(13.0 \%)$ & $10(18.5 \%)$ & $54(24.5 \%)$ & 0.006 \\
\hline No. (\%) caught using sticky traps & $51(54.8 \%)$ & $9(9.7 \%)$ & $2(2.2 \%)$ & $31(33.3 \%)$ & $93(42.3 \%)$ & \\
\hline No. (\%) caught using CDC light traps & $31(42.5 \%)$ & $13(17.8 \%)$ & $12(16.4 \%)$ & $17(23.3 \%)$ & $73(33.2 \%)$ & \\
\hline No. (\%) of flies caught & $105(47.7 \%)$ & $36(16.4 \%)$ & $21(9.5 \%)$ & $58(26.4 \%)$ & $220(100 \%)$ & \\
\hline
\end{tabular}

a Titers were 1:100, 1:200, 1:400, 1:800, 1:1600, 1:3200, 1:6400, 1:12,800, 1:25,600, 1:51,200, and 1:102,400. A titer of $\leq 1: 800$ was considered negative, a titer of 1:1600 was considered as borderline, and a titer of $\geq 1: 3200$ was considered positive

Additional file 2 shows the identification keys used for the identification of the sandflies.

\section{Association between VL, demographic and environmental variables}

The analysis of risk factors associated with VL infection did not reveal a statistically significant association. Regarding the positive participants, all positive participants, $35(100 \%)$ were resident for more than 5 years, P-value 0.567 , while those who live in a thatched house with windows were $57.1 \%$, P-value 0.762 . Also, positive participants who planted Balanites/Acacia trees were 21 (60.1\%), and those who bred domestic animals were 32 (91.4\%), P-values 0.361 and 0.211 , respectively. Of the 35 $(100 \%)$ positive participants who have insects biting compliance, only 20 (57.1\%) were using bed nets as a control method, P-value 0.218 (Additional file 3).

\section{Discussion}

In this study, the detected PCR-positive individuals for whom clinical VL did not develop are considered to be asymptomatic, and they have no history of previous VL infections or treatment, with no clinical signs or symptoms. However, these asymptomatic cases might act as reservoirs for the Leishmania parasite [24] or sustain the parasite transmission in those non-endemic regions [25]. Although the actual estimate of asymptomatic cases and their prospective role in the transmission of $L$. donovani in endemic areas is difficult to assess [26], this may escalate the challenge for the disease control [27]. VL is challenging to diagnose despite the accessibility of numerous diagnostic techniques. A single diagnostic method is not satisfactory to detect all positive VL infections, and the results obtained through multiple diagnostic methods vary from one region to another. The variable diagnostic performance of these methods in VL endemic regions is reflective of the origin of the test-antigen [27-29].

In this study, although higher number of infected persons lived in thatched houses having Balanitis/Acacia trees in/around the house, which is in agreement with other studies that the low financial status and mud/ thatched houses or splintered houses' walls as risk factors for VL [26, 30-34], however, there was no significant association found in this study. Also, most cases of VL were distributed among people having domesticated animals, which is in agreement with other studies, although there was no significant association were found [16, 35-42]. Also, herding of animals in/around the house was considered to have a protective role, where the domesticated animals were acting as a barrier from sandfly bites because the sandflies shifted to feed on the animals [31, 43].

Factors associated with VL may change over time, resulting in conflicting reports of their effect, such as the use of bed nets or implementation of insecticides. Insecticides may not eradicate sandflies since sandflies can persist inside the houses. Additionally, the existence of a vector in a specified area can be misleading hence presence alone does not prove $L$. donovani transmission, which is affected by strain, behavior, seasonal activity, and density of the vector [31, 43].

The proportion of infected patients with $L$. donovani, who may act as a reservoir for in Sudan is barely documented as this requires extensive prospective epidemiological studies. However, no evidence exists demonstrates that individuals with asymptomatic $L$. donovani infection are not reservoirs. Thus, the assessment of those with asymptomatic infections by screening and up to 1-year follow-up is beneficial in VL control. 


\section{Conclusion}

Early treatment of VL-infected patients, mainly asymptomatic individuals will help to reduce disease transmission, as well as mortality.

\section{Limitations}

- Although the results generated from this study provide insights on the status of asymptomatic VL in Sudan, the number of study participants recruited was small due to community incorporation. Therefore, a more extensive study scale is needed to give a clear situation of VL infections in Sudan. As such, the results can, therefore, be used to generalize with caution.

\section{Supplementary information}

Supplementary information accompanies this paper at https://doi. org/10.1186/s13104-019-4608-2.

Additional file 1. Representative samples of the PCR amplification of the 18S rRNA gene of Leishmania parasites.

Additional file 2. Morphological identification of the wild-caught sandfly.

Additional file 3. Association between $\mathrm{VL}$ infection and demographic, household/environmental, behavioral factors.

\section{Abbreviations}

DAT: direct agglutination test; HIV: human immunodeficiency virus; K3-EDTA: potassium ethylene diamine tetraacetic acid; $\mathrm{NaCl}$ : sodium chloride; PCR: polymerase chain reaction; PSC: pyrethroid spray catch; TBE: tris boric acid EDTA; VL: visceral leishmaniasis.

\section{Acknowledgements}

The authors would like to acknowledge the local communities in the study villages for their interest and cooperation in the study. Special thanks to Leishmaniasis Control Program, Gedaref Ministry of Health, Sudan for their logistic and technical support. We also acknowledge Professor El Harith from the Biomedical Research Laboratory of the Ahfad University for Women, Sudan for providing DAT antigen and L. donovani DNA for molecular analysis, and to Dr. Salah-Eldin El-zaki at the Department of Epidemiology, Tropical Medicine Research Institute, National Center of Research, for his support with the filed collection materials.

\section{Authors' contributions}

NSM and AHE provided conceptual framework for the study, guidance for interpretation of the data and performed data analysis. NSM, HAO, AOM, MMAH and AHE performed the field and laboratory work. MSM, EES, AMS, MMAH, RAO, MSA and AA performed the statistical analysis. NSM, EES, HAO, RAO, MSA and AHE participated in the manuscript preparation, revision and coordination. All authors read and approved the final manuscript.

\section{Funding}

Not applicable.

\section{Availability of data and materials}

The datasets used and/or analyzed during the current study are available from the corresponding author on reasonable request.

\section{Ethics approval and consent to participate}

All participants included in the study received comprehensive information concerning the study. Participants were included after signing an informed consent form, agreeing verbally in the case of illiterate participants or in case of children, their parents or legal guardians did so. The study was approved by the community leaders, Gedaref state Ministry of Health and the Department of Parasitology and Medical Entomology, Faculty of Medical Laboratory Sciences, University of Khartoum, Sudan.

\section{Consent to publish}

Not applicable.

\section{Competing interests}

The authors declare that they have no competing interests.

\section{Author details}

${ }^{1}$ Department of Parasitology and Medical Entomology, Faculty of Medical Laboratory Sciences, University of Sinner, 11111 Khartoum, Sudan. ${ }^{2}$ Department of Parasitology and Medical Entomology, Faculty of Medical Laboratory Sciences, Nile University, Khartoum, Sudan. ${ }^{3}$ Department of Molecular Biology, Institute of Zoology, University of Hohenheim, Stuttgart, Germany. ${ }^{4}$ Biomedical Research Laboratory, Ahfad University for Women, Omdurman, Sudan. ${ }^{5}$ Department of Neurology, Mayo Clinic, Jacksonville, FL, USA. ${ }^{6}$ Department of Radiology, Mayo Clinic, Jacksonville, FL, USA. ${ }^{7}$ Department of Internal Medicine, Faculty of Medicine, University of Khartoum, Khartoum, Sudan. ${ }^{8}$ Entomology Department, Faculty of Science, Ain Shams University, Abbassia, Cairo 11566, Egypt. ${ }^{9}$ Department of Parasitology and Medical Entomology, Institute of Endemic Diseases, University of Khartoum, Khartoum, Sudan. ${ }^{10}$ Malaria Control Program and Vector Control, Gedaref Ministry of Health, Gedaref, Sudan. ${ }^{11}$ Department of Basic Medical Sciences, Faculty of Medical Laboratory Sciences, University of Khartoum, Khartoum, Sudan. ${ }^{12}$ Mycetoma Research Center, University of Khartoum, Khartoum, Sudan. ${ }^{13}$ School of Medicine, Nile College, Khartoum, Sudan. ${ }^{14}$ Department of Molecular Biology, National University Research Institute, National University, Khartoum, Sudan. ${ }^{15}$ Faculty of Medicine, Neelain University, Khartoum, Sudan. ${ }^{16}$ Department of Molecular Biology, Institute of Parasitology, University of Leipzig, Leipzig, Germany.

${ }^{17}$ Department of Parasitology and Medical Entomology, Faculty of Medical Laboratory Sciences, University of Khartoum, Khartoum, Sudan.

Received: 3 July 2019 Accepted: 4 September 2019

Published online: 11 September 2019

References

1. Ready PD. Epidemiology of visceral leishmaniasis. Clin Epidemiol. 2014;6:147

2. Osman OF, Kager PA, Oskam L. Leishmaniasis in the Sudan: a literature review with emphasis on clinical aspects. Trop Med Int Health. 2000;5(8):553-62

3. Lahlou H, Filali AB, Alami M, Amrani M, Berrady R, Rabhi S, Bono W. Visceral leishmaniasis in 26 HIV-negative adults. BMC Res Notes. 2011;4(1):389.

4. Oliveira GGDS, Santoro F, Sadigursky M. The subclinical form of experimental visceral leishmaniasis in dogs. Memórias do Instituto Oswaldo Cruz. 1993;88(2):243-8.

5. Mueller YK, Nackers F, Ahmed KA, Boelaert M, Djoumessi J-C, Eltigani R, Gorashi HA, Hammam O, Ritmeijer K, Salih N. Burden of visceral leishmaniasis in villages of eastern Gedaref State, Sudan: an exhaustive cross-sectional survey. PLoS Negl Trop Dis. 2012;6(11):e1872.

6. Archibald RG, Mansour H. Some observations on the epidemiology of kala-azar in the Sudan. Trans R Soc Trop Med Hyg. 1937;30(4):395-406.

7. Zink AR, Spigelman M, Schraut B, Greenblatt CL, Nerlich AG, Donoghue HD. Leishmaniasis in ancient Egypt and upper Nubia. Emerg Infect Dis. 2006;12(10):1616.

8. Baleela R, Llewellyn MS, Fitzpatrick S, Kuhls K, Schönian G, Miles MA, Mauricio IL. Leishmania donovani populations in Eastern Sudan: temporal structuring and a link between human and canine transmission. Parasit Vectors. 2014;7(1):496.

9. Elnaiem DA, Hassan HK, Ward RD. Phlebotomine sandflies in a focus of visceral leishmaniasis in a border area of eastern Sudan. Ann Trop Med Parasitol. 1997;91(3):307-18. 
10. Das VNR, Siddiqui NA, Verma RB, Topno RK, Singh D, Das S, Ranjan A, Pandey K, Kumar N, Das P. Asymptomatic infection of visceral leishmaniasis in hyperendemic areas of Vaishali district, Bihar, India: a challenge to kala-azar elimination programmes. Trans R Soc Trop Med Hyg. 2011;105(11):661-6.

11. Mo'awia MH, Osman OF, El-Raba'a FMA, Schallig HDFH, Elnaiem D-EA. Role of the domestic dog as a reservoir host of Leishmania donovani in eastern Sudan. Parasites Vectors. 2009;2(1):26.

12. Davies $C R$, Gavgani ASM. Age, acquired immunity and the risk of visceral leishmaniasis: a prospective study in Iran. Parasitology. 1999;119(3):247-57.

13. Argaw D, Mulugeta A, Herrero M, Nombela N, Teklu T, Tefera T, Belew Z, Alvar J, Bern C. Risk factors for visceral leishmaniasis among residents and migrants in Kafta-Humera, Ethiopia. PLoS Negl Trop Dis. 2013;7(11):e2543.

14. Tsegaw T, Gadisa E, Seid A, Abera A, Teshome A, Mulugeta A, Herrero $M$, Argaw D, Jorge A, Aseffa A. Identification of environmental parameters and risk mapping of visceral leishmaniasis in Ethiopia by using geographical information systems and a statistical approach. Geospatial Health. 2013;7(2):299-308.

15. Evans TG, Teixeira MJ, McAuliffe IT, Barros Vasconcelos IDA, Vasconcelos AW, de Queiroz Sousa A, de Oliveira Lima JW, Pearson RD. Epidemiology of visceral leishmaniasis in northeast Brazil. J Infect Dis. 1992;166(5):1124-32.

16. Moreno EC, Melo MN, Genaro O, Lambertucci JR, Serufo JC, Andrade ASR, Antunes CMF, Carneiro M. Risk factors for Leishmania chagasi infection in an urban area of Minas Gerais State. Rev Soc Bras Med Trop. 2005;38(6):456-63.

17. Cheesbrough M. District laboratory practice in tropical countries, vol. 1. Cambridge: Cambridge University Press; 1999.

18. El Harith A, Chowdhury S, Al-Masum A, Semiao-Santos S, Karim E, El-Safi $S$, Haque I. Evaluation of cleaving agents other than trypsin in direct agglutination test for further improving diagnosis of visceral leishmaniasis. J Clin Microbiol. 1995;33(8):1984-8.

19. Harith AE, Mutasim ME, Mansour D, Fadil Mustafa E, Arvidson H. Use of glycerol as an alternative to freeze-drying for long-term preservation of antigen for the direct agglutination test. Trop Med Int Health. 2003:8(11):1025-9.

20. Ciulla TA, Sklar RM, Hauser SL. A simple method for DNA purification from peripheral blood. Anal Biochem. 1988;174(2):485-8.

21. Gebresilassie A, Kirstein OD, Yared S, Aklilu E, Moncaz A, Tekie H, Balkew M, Warburg A, Hailu A, Gebre-Michael T. Nocturnal periodicity of Phlebotomus (Larroussius) orientalis (Diptera: Psychodidae) in an endemic focus of visceral leishmaniasis in Northern Ethiopia. Parasites Vectors. 2015;8(1):186

22. Kirk K, Lewis DJ. The phlebotominae of the ethiopian eegion. Ecol Entomol. 1951;102(8):383-510.

23. Abonnenc E, Minter DM. Bilingual keys for the identification of the sandflies of the Ethiopian region. Entomol Med. 1965;5:46.

24. Sharma MC, Gupta AK, Das VNR, Verma N, Kumar N, Saran R, Kar SK. Leishmania donovani in blood smears of asymptomatic persons. Acta Trop. 2000;76(2):195-6.

25. Stauch A, Sarkar RR, Picado A, Ostyn B, Sundar S, Rijal S, Boelaert M, Dujardin J-C, Duerr H-P. Visceral leishmaniasis in the Indian subcontinent: modelling epidemiology and control. PLoS Negl Trop Dis. 2011;5(11):e1405.

26. Chargui N, Haouas N, Slama D, Gorcii M, Jaouadi K, Essabbah-Aguir N, Mezhoud H, Babba H. Transmission of visceral leishmaniasis in a previously non-endemic region of Tunisia: detection of Leishmania DNA in Phlebotomus perniciosus. J Vector Ecol. 2013;38(1):1-5.

27. Abass E, Kang C, Martinkovic F, Semião-Santos SJ, Sundar S, Walden P, Piarroux R, El Harith A, Lohoff M, Steinhoff U. Heterogeneity of Leishmania donovani parasites complicates diagnosis of visceral leishmaniasis: comparison of different serological tests in three endemic regions. PLOS ONE. 2015;10:3.

28. Singh DP, Sundar S, Mohapatra TM. The rK39 strip test is non-predictor of clinical status for kala-azar. BMC Res Notes. 2009;2(1):187.

29. Kiros YK, Regassa BF. The role of rk39 serologic test in the diagnosis of visceral leishmaniasis in a Tertiary Hospital, Northern Ethiopia. BMC Res Notes. 2017;10(1):169.

30. Elnaiem D-EA, Schorscher J, Bendall A, Obsomer V, Osman ME, Mekkawi AM, Connor SJ, Ashford RW, Thomson MC. Risk mapping of visceral leishmaniasis: the role of local variation in rainfall and altitude on the presence and incidence of kala-azar in eastern Sudan. Am J Trop Med Hygiene. 2003;68(1):10-7.

31. Kolaczinski JH, Reithinger R, Worku DT, Ocheng A, Kasimiro J, Kabatereine $\mathrm{N}$, Brooker S. Risk factors of visceral leishmaniasis in East Africa: a casecontrol study in Pokot territory of Kenya and Uganda. Int J Epidemiol. 2008;37(2):344-52.

32. Zijlstra EE, El-Hassan AM. Visceral leishmaniasis. Trans R Soc Trop Med Hyg. 2001;95:S27-58.

33. Alvar J, Yactayo S, Bern C. Leishmaniasis and poverty. Trends Parasitol. 2006;22(12):552-7.

34. Mengesha B, Endris M, Takele Y, Mekonnen K, Tadesse T, Feleke A, Diro E. Prevalence of malnutrition and associated risk factors among adult visceral leishmaniasis patients in Northwest Ethiopia: a cross sectional study. BMC Res Notes. 2014;7(1):75.

35. Heisch RB, Guggisberg CAW, Teesdale C. Studies in leishmaniasis in East Africa II. The Sandflies of the kitui kala-azar area in Kenya, with descriptions of six new species. Trans R Soc Trop Med Hyg. 1956;50(3):209-26.

36. Robert LL, Schaefer KU, Johnson RN. Phlebotomine sandflies associated with households of human visceral leishmaniasis cases in Baringo District, Kenya. Ann Trop Med Parasitol. 1994;88(6):649-57.

37. Ryan JR, Mbui J, Rashid JR, Wasunna MK, Kirigi G, Magiri C, Kinoti D, Ngumbi PM, Martin SK, Odera SO. Spatial clustering and epidemiological aspects of visceral leishmaniasis in two endemic villages, Baringo District, Kenya. Am J Trop Med Hyg. 2006;74(2):308-17.

38. Saha S, Ramachandran R, Hutin YJF, Gupte MD. Visceral leishmaniasis is preventable in a highly endemic village in West Bengal, India. Trans R Soc Trop Med Hyg. 2009;103(7):737-42.

39. Picado A, Ostyn B, Singh SP, Uranw S, Hasker E, Rijal S, Sundar S, Boelaert $\mathrm{M}$, Chappuis F. Risk factors for visceral leishmaniasis and asymptomatic Leishmania donovani infection in India and Nepal. PLoS ONE. 2014;9(1):e87641.

40. Bern C, Hightower AW, Chowdhury R, Ali M, Amann J, Wagatsuma Y, Haque R, Kurkjian K, Vaz LE, Begum M. Risk factors for kala-azar in Bangladesh. Emerg Infect Dis. 2005;11(5):655.

41. Barnett PG, Singh SP, Bern C, Hightower AW, Sundar S. Virgin soil: the spread of visceral leishmaniasis into Uttar Pradesh, India. Am J Trop Med Hyg. 2005;73(4):720-5.

42. Schenkel K, Rijal S, Koirala S, Koirala S, Vanlerberghe V, Van der Stuyft P, Gramiccia M, Boelaert M. Visceral leishmaniasis in southeastern Nepal: a cross-sectional survey on Leishmania donovani infection and its risk factors. Trop Med Int Health. 2006;11(12):1792-9.

43. Bern C, Joshi AB, Jha SN, Das ML, Hightower A, Thakur GD, Bista MB. Factors associated with visceral leishmaniasis in Nepal: bed-net use is strongly protective. Am J Trop Med Hyg. 2000;63(3):184-8.

\section{Publisher's Note}

Springer Nature remains neutral with regard to jurisdictional claims in published maps and institutional affiliations. 